\title{
Urban traces: revitalization strategies for abandoned villages
}

\section{Letizia Gorgo, Gloria Riggi}

Dipartimento di Architettura e progetto. Sapienza, Università di Roma, Italy

E-mail: letiziagorgo@hotmail.it, gloriariggi@libero.it

\begin{abstract}
Research In Italy today, one can count more than 6000 villages that have been abandoned(deserted) for a variety of causes. This negletc state produces a serious problem related to a wider phenomenon of abandonment of entire portions of italian territories. Realities that differ form the city because of their morphology: Does urban shape represent an urban limit? or is it an alternative testimony to the city? Research purpose is to understand how relationship, between these cases and the territory, works; in particular during the absence of the main component: the human one. The case study Santo Stefano di Sessanio, an ancient village in the center of Italy, inhabited until 90's, shows how the examination of urban shape represents the potentiality of his own revitalization. By relating his historical identity to the scattered hotel projectual approach, it contributes to combine conservation, valorization and sustainability of the existing building fabric, in order to claim the authenticity of these villages declaring their own autonomy and dimension to major urban centers polarization. In this example transformation is meant as conscious project that grow up from the built reality not from the project itself, transformation as knowledge of urban facts, tool to approach to the structure of this reality.
\end{abstract}

Keywords: Abandoned villages, urban morphology, scattered hotel, existing fabric, revitalization strategies.

\section{Introduction}

The origin of this reflection comes from the realization that man's intervention on the land, his presence, always leaves traces, triggering a process of interaction between anthropic action and the regional system. To talk about this process does not solely entail the issue of time, but also, it opens up to a much complex understanding in which process turns into analysis, reality's reading and design. The core of this theoretical-strategic research lays here. Territory subjected to human transformations, outcome, in turn, of previous modifications; a dynamic reality that draws from experiences in order to create future prospective. Design project then, has to be able to read this intricate weave and carry the new traces that will combine with those of the already existing reality. The action of designing has to follow morphological analysis, whose role is that to study the unrevealed logics of our constructed reality, taking into account cultural, social and political factors.

The case study taken into consideration, that of Italian villages, deals with a reality whose process of construction seems to be crystalized, so much so that it has undone its potential and has been caught in a standoff, with the consequence of total abandonment.

These villages are immersing in the rural Italian countryside, they are sometimes hard to reach, and nonetheless, they have been able to confront a harsh environment. In the course of centuries, they have been able to tame nature thanks to the work of human beings; however, they are now frozen in the time of the "unreal", in the state of total abandonment. To 
consider these realities as a synthesis between territory and human labor allows transforming a contemplative conception of nature into an architectonical one. The etymology of the term ?Architecture', derives from archè e teknè, which intervene in the landscape giving origins to what German architects call Kulturlandshaft, "cultural landscape"1. Within this frame there are the concepts of time, history, and operating history, in which knowledge and architecture identify with reality, as exemplified in the study of the architect Saverio Muratori in the 50s: "This is how it has been possible to include the new into the ancient in a unitary subject: through a process of subsequent integrations where the individual's personality and the spirit of an age embrace the heritage of the predecessors and their past and complete it with originality, thanks to a continuous operation, an endless action towards creation. Such a process is typical of architecture which, is at the same time, a work of the individual and the collective, of art, which is creation and tradition of the culture it comes from, and of life itself, which is always originality and preservation." He goes on as follows: "the anatomy of an urban organism is to be understood and studied in its layout, in its "building fabric", in the way it integrates itself in the environment, in order for it to be developed and interpreted, not distorted." "The transformation of an old urban unit is a venture neither for improvisers, nor for speculators, nor for ambitious ones [...] the strictest and most vigilant control needs to be opposed to such strengths, yet, at the same time, a technical, legal and administrative organization needs to be developed for the protection of old urban units[...] and, even before this, a cultural movement among public, scholars and architects that deal with the issue with the aim of spreading interest for the city's history by elevating it to moral value. Without this, legal and administrative measures, even if approved, are not going to be applicable." 2 . This setting-out allows restarting from these "unreal" realities, given their estrangement to the contemporary life, in such a way that it is possible to rethink about their revitalization, about human intervention in a way that allows for their continuation in the human and architectonic process, the very survival of this immense heritage.
Urban morphology seems to furnish the necessary tools not only for the analysis of these realities, but also for a conscious and wise intervention on them, thanks to the very fact that it operates through those same essential aspects of cultural landscape: nature and human action. In this manner, the analysis of the urban fabric becomes essentially metadesigning. This dimension is fundamental if we want to operate in a context as complex as that of small rural mountain villages, which have to recover, or better propose again, their identity in the contemporary society. Regarding the role of architecture in this context, Pigafetta, referring to Muratori's work, wrote: "It was not that Muratori wanted to simply propose study instruments for the formation and development of the urban fabric, it was not a matter of detecting spaces of confrontation, more or less dialectic, between "the old and the new", it was not about finding fortunate itineraries for restoration and reuse. It was rather about establishing an "operative" relationship with historical architecture, in such a way that, instead of simply creating the condition to intervene on it, disciplinary norms for architectonic design tout court would emerge, independent from the historicity of the context."3

The historical dimension has to be at the center of architectonical reasoning, not in an exclusive way but rather it is a necessary step to further include the future and essential actions of the architect. This type of acknowledgement will be then the guide for actions of tutelage and safeguard of these realities4.

The study of the urban morphology of these minor realities, blocked in the time of unreality, is particularly interesting if one also wants to investigate on the collective dimension of architecture and its role in contemporary intervention as process in act. Therefore, the case study taken into consideration is useful because the reading of the area has allowed for a further passage, the revitalization of these minor centers through programs that are fully respondent to the needs of contemporary collectivities. It is therefore the expression of values added to the already existing traces deposited on this constructed reality. These 
designs let us read the past, treasure it, and also continue the process in act in these cultural landscapes. Specifically, the idea of sustainable tourism that materializes through the planning of "diffused hotels" allows operating according to what has been said.

"To do it is not more than the means for which we participate to the natural world" 5 . We can add to these words the term "sustainable", to do "sustainably".

The definition of sustainability implies a vision of globalism, in the sense that it is not possible to understand it as the outcome of technical thinking, attached to the technical performance of a building or, more generally, design. Sustainability has to be understood interdisciplinary, meaning the sustainable doing of man on earth. This is the fundamental premise for a new global society. This conceptual mark intends to use the land, already the protagonist of anthropic action, in a way that accounts for the needs of a society that is more and more driven to consumption.

The principle of consumption per se, more than consumption and reuse, has given origin to a series of episodes that constellate our reality. The scenery of abandoned Italian villages seems to be one of them.

Taken into consideration the past life of these urban sceneries, one realizes that a sort of balance between nature and human labor governed them. To restart from these settlements, whose abandoning shows the paradigmatic change in post-industrial societies, means attempting to re-establish this lost but necessary balance.

This new conception of global sustainable society needs the return of those forms of territorial living.

Obviously, the recovery of the villages has to be reasoned and measured according to the needs of a new society, since rural lifestyle does not apply to places that have been abandoned precisely because of the negation of this rurality. However, architectonic design can intervene thanks to the subtle formative logics of these settlements, in order to carry new values, or better, re-discover those forgotten values that have been left together with physical places. These realities are in fact witnesses of building, social and cultural traditions that run the risk of being forgotten by contemporary society, because they are attached to specific weather, habits and local materials. Once one recuperates these aspects, revitalization comes through sustainability, because it answers those same dispositions of the local scenery that once sought sustainability as the solution to everyday problems, the only possible form of survival.

The theme of revitalization in these minor historical centers of immense heritage becomes a strong necessity once the identity of the place is strengthen by the rethinking of the villages in terms of economic, social and architectonic development. Identity and cultural values should be at the center of the strategies for recovery. Moreover, to interpret this recovery in terms of economy and tourism is also extremely contemporary. The National Observatory of Tourism accounts for the growing importance of integration between tourism and local realities: "According to the WTO (World Tourism Organization), cultural tourism represents the moving of people for cultural scopes, such as study holiday, live shows, festivals, cultural events, visits to archeological sites and monuments, and pilgrimages. Cultural tourism also involves the pleasure of plunging into local lifestyle and everything that constitutes its identity and character."6

In 2010, the plan "Europe 2014-2020" has been approved. It states: "In line with the new priorities of the European Union, as established in "Europe 2020", and for the purpose of maintaining the European primacy of main global tourist destination, the Commission proposes a new plan of coordinated actions for tourism on the EU level for the purpose of strengthening competition and sustainable growth for European tourism." 7

In the "European Pact Villages 2020" will be taken into consideration, especially the strategic importance of giving value to abandoned villages through tourism as engine of growth and territorial development in European countries. 8

According to Istat results, small districts9 (less than 5000 inhabitants) are 5693. This is a generic classification, since many of 
these municipalities are included in this case study records, which deals with those villages that with the advent of modernity have been gradually abandoned. Villages have a specific morphological structure: there is a square, households around, a fortification and a market. This structure was fundamental for survival in the medieval period, and it furnished those conditions of historical and cultural integrity that have collapsed with industrialization. This happened because of the exclusion of small-scale rural economy from the necessity of a society that was going through a process of rapid development. During the IIWW aftermath, these lands have seen the gradual fading away of vitality. The 50 s have in fact seen significant modifications in the relationship between people and land, caused by the industrial revolution and the development of transportation. The importance of a given residential area begins to depend on the infrastructural networks it has to offer to its hinterland. The rail system represents the measure of this capacity. During the 60s, the economic boom in Italy also raises the demand for households in big cities, with the consequence of abandonment of the rural world. Cars become the best way to move, together with the development of roads. This, in turn, exasperates the attitude towards small historic centers that are difficult to reach and lack those characteristics that the modern world needs.

These ghost towns start constellating the national territory. Abandoned villages maintain their untouched characteristics as if the clock has stopped. This implies also the progressive erasing of their cultural and social connotations. Better, their desertion does not imply that the heritage disappears, as they surely deteriorate but remain intact and untouched, but the custodians of their memory are human beings, visitors, inhabitants that with their fruition allow the reactivation of the historical memory of places.

The study of this situation is not exhaustive in terms of both general knowledge and architecture. Researches were made by public organizations such as Legambiente e privare, gruppo Norman Brian. 10

It is a study conducted by Confcommercio-
Legambiente, "Italy and dwell's disadvantage" 11 , that reveals the actual conditions: "If in 1996 "dwell's disadvantage" hit 2.830 municipalities, in 2006 there were 3.556 of them, with the prospect of 4.395 in 2016 (one very two) and 1650 ghost towns, risking extinction". To continue with the analysis of studies already conducted, the group Norman Brian has some saying on "Ghost Towns": "the project was born out of the observation of a common phenomenon in Italy; the death of villages and villages primarily involves the more isolated communities, far from big cities, or those realities close to dangerous areas in terms of natural or water disasters. Their position, far away from transport junctions, has prevented their growth, and migration towards Italian and foreign big cities, especially in the 50s, has established their slow decay." 12

This being the general picture, in which way can architecture intervene in the name of tutelage of this collective cultural heritage?

The impact of the phenomenon of dwell's dismissal, and the consequent loss of the social, cultural and economic role of these realities requires the fine tuning of a strategy in which architecture, understood as reality's reading and a type of design that takes into consideration the continual role of history, can and must have a leading role.

It is not enough to talk in terms of tutelage and physical conservation of buildings, better, the architect has to be part of the economic, social and cultural process that has in mind the second life of these Villages. Were this not the case, we would face an even worst situation: the musealization of historical centers, a declaration of defeat in respect to all of those processes that led to the decay of these realities. Regarding the strategy of intervention, there are some interesting records of various local contexts. A review of concrete experiences of reactivation of small centers, thanks to several initiatives, seems to prefigure an effective modality of answer to the problem.

The discourse of the physical requalification of these minor centers, in fact, cannot be detached from the dwell's option. It still remains the parameter of confrontation for operations of recovery: for who one recovers, 
and how the design finds innovative solutions for both the values of the past and the present needs of potential inhabitants.

We can talk about inhabitants in many ways. Inhabitants are those who visit, who decide to live the experience of tourism and come back year after year; inhabitants are the elders, who might decide to live in a village for their retirement; inhabitants are those migrants that move and bring new habits and lifestyles, reactivating the economy; but also workers who pick a small-scale type of industry to install new and alternative modes of business.

The key to success of all these experiences of requalification consists on the capacity to be replicable, the ability to integrate with other options of governance according to privatepublic administrative synergies in a systematic vision that involves the entire country as the ultimate deposit of processes of requalification.

The term "management of the landscape" means all those actions that, having in mind a prospective of sustainable development, assure a regular and balanced evolution of the landscape to guide those passages of social, economic and environmental transformation. The term "management" implies the presence of the human component, without which the above-said process would not be possible. In fact, article 1 of the European Convention for the Landscape cites: "Landscape designates a specific part of the territory, as perceived by its people, whose character derives from the action of nature and/or man and their interaction"; landscape can be imagined as a continuum of natural and human-technological systems, in which the latter acquires more and more power in terms of influence on the land. Moreover, the term "perception" refers to two components, the visual and the social. Both indicate the way in which man lives and produces the notion of landscape.

It is therefore necessary to understand that "built city" is not "lived city", as the container in not the content, as the former contains and molds the latter, and so it plays a fundamental role of social identity.

This definition reveals the importance of the human factor in this type of realities (village, hamlet, etc.). When this misses how is it possible to intervene? Does intervention legitimize the existence of village that would otherwise cease to exist? What kind of perception would one have of a given landscape?

\section{The study case of Santo Stefano di Sessanio}

The case of Santo Stefano di Sessanio in Abruzzo is a good example of this, because it exemplifies the reasoning of this research. It is a fortified medieval village on top of the hill of Gran Sasso, $1250 \mathrm{mt}$, surrounded by mountains. It is also part of the National Park of Gran Sasso and the mountains of Laga. It has Roman foundations. In the VIII century Santo Stefano di Sessanio and the surrounding lands become Langobardic possession, determining the repopulation of the countryside and the construction of new types of dwellings, such as the agglomeration of households and walls around the castle. From the 1600 on, Medici's family intervention is a constant presence. They contributed to the restauration of the tower, the intervention on the church of Santo Stefano Protomartire, and the building of many of the courts, patios and loggias with doublearched and decorated windows. Starting from the 1900, the phase of decay follows the crisis of mountain agriculture and the growing deindustrialization13, reaching the level of 142 inhabitants in 1991 (ISTAT).

At the end of the 90s, Daniele Kihlgren, a foreign entrepreneur, buys part of the village with the intention of recuperating its historic, cultural and artistic heritage. His approach is multidisciplinary. It blends humanistic and philosophical culture with anthropology, architecture and economy, as his choice of "diffused hotel" represents a relevant economic value for demographic and economic growth. The starting point of intervention is tutelage of real estate: conservation of the original cubing, of the typological implants, destination of use and holes. Recyclable materials were taken from the surrounding areas, to assure the involvement of local economies. Different uses are assigned to different buildings: hotels, private residences, restaurants, shops, taverns, workshops, areas for free time, etc., all within the village. 
Some data on the intervention:

$4000 \mathrm{~m} 2$ area of intervention

42 rooms

8 common areas

Restaurant

Polyvalent room

6 workshops

In 2001 the spare households were around $75,5 \%$, in 2012 the percentage is almost $0 \%$, with around 7300 presences per year and more than $30 \%$ of employment, exponential growth was registered thanks to hotels, when in 2001 there were only three14 of them, finally, $90 \%$ increase of real estate worth between 2006 and 200815.

Many private businesses became sponsors, public organizations such as the Municipality of Florence, the Ministry for Cultural Activities, the Ministry of Tourism help supporting the cause. Moreover, there have been the revitalization of forgotten jobs and professional figures, a positive impact on local agriculture and a significant wave of tourism. All these aspects help us framing the case as a paradigmatic example for similar realities.

This is a global resource, because it combines different aspects and also draws from the characteristic urban traces of a given area and transforms them into strategies of revitalization.

\section{Notes}

1.To deepen the topic about cultural geography, see Von Humboldt, A., Kosmos, 1845-1847 2.Quote from Muratori, S., Vita e Storia delle Città, in "Rassegna critica di architettura", n. 11-12, 1950, pp. 3-52

3. In Pigafetta, G., Saverio Muratori architetto. Teoria e progetti, Marsilio Editori, Venezia, 1990

4. In Pigafetta, G., review to B.P. Torsello, La materia del restauro, Venezia 1988, in Eidos, 4, 1989 pp. $106-108$

"The very first meaning of tutelage derives from the Latin "tueor" which means to look, to contemplate, take care, a form of tutelage that recalls the act of looking at, before possessing or having something at disposal. Teuor goes together with another Latin verb, "respicio" (respect) which has a similar connotation, that of looking behind, from a far distance. To look, to contemplate is necessarily connected to knowledge. Not only in terms of intuition (in-teur, look inside) but also in the translated form of "ratio", or "intelect" (intelego, look, understand, represent, imagine). Like Heidegger, and Husserl before, the semantic root of id-idein reminds of the act of looking. It is a fundamental trait of our culture" (my translation)

5. In Muratori, S., Storia e critica dell'architettura contemporanea, 1944, opera postuma a cura di Marinucci, G., Centro studi di Storia Urbanistica, Roma 1980, p. 87

6. National Tourism Observatory - Italy - Drafting NTO, 19-02-2013, http://www. ontit.it/opencms/opencms/ont/it/focus/ focus/Seminario_Il_valore_del_patrimonio_ culturale_idee_a_confronto

7.Federturismo Confindustria, http://www. federturismo.it/it/federazione/federturismobruxelles/lattivita-dellue-per-il-turismo-menuorizzontale-574

8.file:///C:/Users/letiz/Downloads/ Allegato\%20IV-\%20Patto\%20europeo\%20 Borghi\%202020\%20\%20-w03.pdf

9.http://www.comuniverso.it/index. cfm?menu $=590$

10.M. Bassanelli, Geografie dell'abbandono, progetto del gruppo di ricerca, DPA, Politecnico di Milano, luglio 2010

11.1996/2016, Eccellenze e ghost town nell'Italia dei piccoli comuni, in collaboration with Serico-Gruppo Cresme.

12. Quote from Paesi Fantasma. Tesori nascosti dell'Italia minore, 23th June 2005. In Bassanelli, M., Geografie dell'abbandono, p. 42.

13. L. Klarmann, Rivitalizzazione dei nuclei storici minori. L' esempio dell'albergo diffuso, Tesi di laurea in Architettura Ambientale, Politecnico di Milano, 2014, p.17

14.Source SEXTANTIO S.p.a.

15. Source Agenzia delle Entrate 


\section{References}

Muratori, S., (1950) 'Vita e Storia delle Città', Rassegna critica di architettura, n. 11-12, pp. 3-52.

Muratori S., (1967) 'Civiltà e territorio', (Centro studi di storia e urbanistica, Roma, IT).

Cartei, G. F., (2007) 'Convenzione europea del paesaggio e governo del territorio'.

Pigafetta, G., (1990) 'Saverio Muratori architetto. Teoria e progetti', (Marsilio Editori, Venezia).

Bassanelli, M., (2010) 'Geografie dell'abbandono', progetto del gruppo di ricerca, DPA, Politecnico di Milano.

Maretto, M., (2012) 'Ecocities. Il progetto urbano tra morfologia e sostenibilità', (Franco Angeli, Milano).

Piane, F., (2014) 'Sextantio Albergo Diffuso: la replicabilità del modello in Calabria', unpublished Masters Degree thesis in political science.

Klarmann, L., (2014) 'Rivitalizzazione dei nuclei storici minori. L' esempio dell'albergo diffuso', unpublished Masters Degree in Architecture, (Politecnico di Milano, IT).

Strappa, G., Carlotti, P., Camiz, A., (2016) 'Morfologia urbana e tessuti storici. Il progetto contemporaneo dei centri minori del Lazio', (Gangemi Editori, Roma).

Pirlone, F., (2016) 'I borghi antichi abbandonati. Patrimonio da ricoprire e mettere in sicurezza', (Franco Angeli, Milano).

Caravaggi L., (2014) 'La montagna resiliente', (Quodlibet, Macerata).

http://santostefano.sextantio.it

http://www.ontit.it/opencms/opencms/ont/ it/focus/focus/Seminario_Il_valore del_patrimonio_culturale_idee_a_ confrontohttp://www.federturismo.it/ it/federazione/federturismo-bruxelles/ lattivita-dellue-per-il-turismo-menuorizzontale-574 